\title{
A New Combined Approach of Technology Acquisition Using Priority Setting: A Case Study of Membrane Technology
}

\author{
Mostafa Jafari \\ Industrial Engineering Department, Iran University of Science \& Technology (Tehran), Iran \\ E-mail: jafari@iust.ac.ir \\ Mahdi Sahafzadeh (Corresponding author) \\ Industrial Engineering Department, Iran University of Science \& Technology (Tehran), Iran \\ E-mail: sahaf@ind.iust.ac.ir
}

\begin{abstract}
In this paper an overall approach of technology acquisition by using a priority setting method is proposed. In the management of technology literature, different methods of Technology Acquisition were developed. We categorized them into three levels: mode, mechanism and operational models. In this paper we developed an algorithm for choosing the best mode of technology acquisition in the specific technology. The algorithm is combination of critical technologies method and some criteria such as cost of technology acquisition mode. Concurrently priorities of technologies will be set. Finally we applied this approach to membrane technology in Iranian petrochemical industry.
\end{abstract}

Keywords: Technology Acquisition Method, R\&D Priority Setting, Membrane Technology

\section{Introduction}

Generally, from studying the references such as Porter's model, Hax and majluf, A.D.little, D'Aveni, Itami and Numagami, Booz-Allen \& Hamilton and Chiesa R\&D strategy formulation models, it is found that a firm's R\&D strategy consists of "the definition of the set of R\&D projects required achieving the fixed objectives in terms of technology acquisition defined within the overall strategic framework of the firm" (Chiesa, 2001). This definition addresses some critical concepts which are worth to be further attention:

- The actual output of an R\&D strategy is a set of R\&D projects to be undertaken,

- The technology is not good per se but has to be useful to achieve the firm's overall objectives and therefore there needs to be consistency between the R\&D strategy and the firm's overall strategy

- The objective of an R\&D strategy is the acquisition of technology (where acquisition is meant as both internally developed and externally acquired, including the variety of collaborative forms) (Chiesa, 2001).

The third critical dimension of a technology strategy is the mode of technology acquisition, which means to define whether to develop technologies through internal development, coordinating with other firms or institutions, or buying the technology. This section deals with the strategic factors affecting a firm's choice of the acquisition mode and the relation of this with the selection of the technologies and timing of technology development and introduction. The selection of the appropriate form of technology acquisition and the organizational implications of the different modes of technology acquisition from external sources are practiced by several ways.

When technology acquisition is considered, actually, a distinction should be made between technology development and technology introduction. In the phase of technology development, external sources can be assessed to acquire the technological competencies. In the phase of technology introduction the decision concerns whether to acquire the resources necessary to commercialize a technology. Whereas in technology development the decision concerns whether to develop the technology internally, to cooperate or to buy the technology from external resources, in the phase of technology introduction the decision concerns whether to resort on internal resources, to cooperate with other firms to access the required resources or to sell technology. Therefore, although there may be inter-relations between the two decisions, there are factors which are relevant to the development activity and others which are relevant to the introduction phase. 


\section{The Model}

By analysis of methods and using some criteria, an algorithm was developed to select both priorities of technologies and the best way of acquisition mode for prior technologies. In the algorithm critical technologies method was used. Especially the Feasibility- Attractiveness matrix in the foresight context was utilized. Also in technology development, some variables affect the decision about whether to develop internally, cooperate or buy. These factors are like Availability and level of external sources, Time, Appropriability, Technical Risk and Familiarity with Technology, Learning Acceleration or Costs. In this project based on the situation of the country the most critical variables was chosen. These are: Availability and level of external sources based on the political situations and cost of technology acquisition.

\subsection{Availability and level of external sources}

A first obvious factor and a pre-requisite for the external acquisition of technology is the availability and the quality of the external sources of the concerned technology. Especially, if the results the firm is aimed to achieve are already available elsewhere and can be acquired, it looks rather obvious to avoid a strain on the firm's funds and access such findings.

\subsection{Costs}

Costs of technology acquisition usually decrease if the acquisition takes place accessing external sources. The sharing of resources among partners reduces development costs. However, this reduction may be significantly lower than expected if the time (and therefore the resources) spent to set up the collaboration is long. The cost of buying a technology may strongly vary, depending on the contractual power and the types of contract (exclusiveness, property rights, etc.).

\subsection{Feasibility-Attractiveness Matrix}

The main objective of using this matrix sounds quite simple: to reduce the initial list of technologies to a list of critical technologies that are the most relevant against the set of applied criteria. However, since prioritization may discard a substantial number of technologies considered so far, there are suddenly "the winners" and "the losers". It is at this point that strong lobbying usually takes place and it is one of the most important tasks for the team managing the exercise to keep the results protected from external pressures as much as possible.

In practice, a voting procedure is usually used to make a selection from the initial list of technologies. In this model, the Feasibility-Attractiveness matrix is proposed which is used in CSIRO and Czech Republic foresight programmes. The parameters attractiveness and feasibility are determined for each technology from the initial list. Technologies having a good score for both parameters are potential candidates for the final list of critical technologies. Both parameters have a complex character: they result from values of individual criteria that were assigned by voters to individual technologies from the initial list. The result can then be depicted in a two dimensional graph with both objectives as variables for each of the technologies. Here this matrix was used both for ranking technologies and selecting the acquisition mode of prior technologies.

According to Morin matrix segmentation and its strategies, we propose about these 3 regions of the matrix, 3 strategies: if the technology occurs in a region A, so it is a key technology with high feasibility, so inside the industry can invest and work on it. Internal R\&D would be appropriate choice but the team identified two more criteria for making decision about acquisition type: first one is about the political situation of the country whether is possible technology transfer and external acquisition or not? The second is cost of internal R\&D vs. external acquisition. Based on these three questions the team were designed an algorithm and applied it to the prior technologies. In the figure 1 the algorithm is shown.

In this algorithm five decision points was designed. The first three ones relate to F-A matrix and the last ones are direct variables of mode selection which is described in the next section through the case study.

\section{Case Study: Priority Setting of Membrane Technology in Petrochemical Industry}

In this section, result of applying this model in the petrochemical industry of Iran for finding the best acquisition mode of priorities of membrane technology will be described.

\subsection{Case Description}

Crude oil and natural gas after production from well are using in different areas. Petroleum refining is the physical, thermal and chemical separation of crude oil into its major distillation fractions which are then further processed through a series of separation and conversion steps into finished petroleum products. These products make great value added. The primary products of the industry fall into three major categories: fuels (motor gasoline, diesel and distillate fuel oil, liquefied petroleum gas, jet fuel, residual fuel oil, kerosene, and coke); 
finished nonfuel products (solvents, lubricating oils, greases, petroleum wax, petroleum jelly, asphalt, and coke); and chemical industry feedstocks (naphtha, ethane, propane, butane, ethylene, propylene, butylenes, butadiene, benzene, toluene, and xylene) (Hawkins, 1992). So there are lots of processes and technologies in petroleum refineries. Membrane technology is one of the most important technologies in this field.

\subsection{Priority Setting}

Based on the Petrochemical Industry Scope in Iran, 32 technologies were identified. According to CSIRO method, attractiveness is composed from potential benefits and industry's ability to capture benefits. Also feasibility is composed from R\&D potential and R\&D Capacity. For evaluation of each factor it is needed to use some criterion. After searching through internet, documents and some reports a list of useful criteria was generated and adjusted to this field by expert opinions in expert panels.

Evaluation of these criteria was done by expert interviews and filling of questionnaire designed based on those criteria. Totally 22 questionnaire was sent to experts of membrane technology and filled correctly and completely.

Aggregation of results and normalizing them between 0 and 9 revealed the score of each technology which is shown in table 1 .

We put the results gained by questionnaires in the Feasibility-Attractiveness matrix which is a two-dimensional analytical matrix. In figure 2 the position of 32 technologies according to these factors are shown. The matrix is divided to three regions by two separating lines. In the first part the technologies with the highest level of attractiveness and feasibility are located. In the other word priorities are technologies of region A. By putting result in the algorithm, the Internal $R \& D$ strategy for this region was proposed. In the second region there are technologies with selective investment strategy i.e. depends on other factors such as availability of resources or dependency to technologies of region A, they would be selected. Finally the least level of priority are located in the third region. According to the algorithm, appropriate strategy for these technologies is forgiving them.

Finally, decision on buy vs. internal R\&D vs. external acquisition of critical technologies was made. The result of the all three priority was the same: internal R\&D. the findings of the algorithm for each technology is shown in table 2.

\section{Conclusion}

In this paper we developed an algorithm for finding the mode of technology acquisition for Membrane Technology in the Iranian petrochemical industry. This algorithm uses foresight approach and critical technologies method. The categorization of feasibility-attractiveness matrix was done and used in the 3 decision points of algorithm. Also two factors of political situation and partial cost of acquiring technology were determined. By applying this algorithm, simultaneously both of priorities and mode of acquisition were suggested.

\section{References}

Booz- Allan \& Hamilton. (1981). The strategic Management of Technology. Outlook, Fallwinter.

Chiesa, V. (2001). R\&D Strategy and Organization.

D'Aveni R.A. (1994). Hypercompetitive rivalries - Competing in highly dynamic environments. Free Press, New York.

EPA. (1995). Profile of the Petroleum Refining Industry, EPA report.

Hamel, G. and Heene, A. (1994). Competence Based Competition. John Wiley \& Sons, Chichester.

Hawkins, R.G. (1992). Economic Evaluation of CSIRO Industrial Research. CSIRO Institute.

Hax A.C. N.S. Majluf. (1996). The Strategy Concept and Process: A Pragmatic Approach. Prentice Hall.

Itami, H. and Numagami, T. (1992). Dynamic interaction between strategy and technology. Strategic Management Journal, vol. 13, p119 - 135.

Little, A. D. (1981). The Strategic Management of Technology European Management Forum, Davos.

Madaeni, S.S. (2006). Gas Separation with Membranes, Razi university publishing.

Morin J. (1985). La Excellence Technologique, Edition Jean Picollec, Paris.

Porter A. et al. (1991). Forecasting and Management of Technology. John Wiley \& Sons.

UNIDO TECHNOLOGY FORESIGHT MANUAL. (2005). volume 1, 2. 
Table 1. Summation of questionnaire results

\begin{tabular}{|c|c|c|c|}
\hline ID & Technology & Total Feasibility & Total Attractiveness \\
\hline 1 & Hydrogen Separation & 56.08115 & 59.11544 \\
\hline 2 & Air Separation & 56.48459 & 45.77016 \\
\hline 3 & Hydrocarbon Separation & 60.10342 & 58.38853 \\
\hline 4 & Dehydration & 52.89141 & 44.90183 \\
\hline 5 & MTBE dehydration & 35.31583 & 26.34469 \\
\hline 6 & VCM dehydration & 34.88735 & 23.86635 \\
\hline 7 & Glycols dehydration & 28.57395 & 31.77697 \\
\hline 8 & EDC dehydration & 35.06129 & 26.40469 \\
\hline 9 & Methanol $/ \mathrm{H}_{2} \mathrm{O}$ & 31.92156 & 35.81428 \\
\hline 10 & Benzene/ $\mathrm{H}_{2} \mathrm{O}$ & 41.06825 & 33.20991 \\
\hline 11 & Butanol/ $\mathrm{H}_{2} \mathrm{O}$ & 31.79011 & 31.34515 \\
\hline 12 & Ethyl Benzene / Styrene & 32.87716 & 26.84507 \\
\hline 13 & Ethyl Benzene / xylene & 30.80929 & 22.80683 \\
\hline 14 & Xylene Isomers Separation & 30.80929 & 25.71429 \\
\hline 15 & Benzene / Gasoline & 29.83621 & 24.30166 \\
\hline 16 & Methanol / MTBE & 31.05964 & 24.69296 \\
\hline 17 & Esterification & 58.24362 & 29.25915 \\
\hline 18 & Dehydrogenation & 43.78828 & 40.1394 \\
\hline 19 & Synthesis Gas Production & 42.36194 & 38.57953 \\
\hline 20 & Oxidative Coupling Methane (OCM) & 48.95204 & 37.81405 \\
\hline 21 & Reverse osmosis & 47.22949 & 50.55674 \\
\hline 22 & Nanofiltration & 49.11246 & 48.43168 \\
\hline 23 & Ultra filtration & 51.20729 & 47.88265 \\
\hline 24 & Microfiltration & 56.35427 & 48.48747 \\
\hline 25 & Membrane bioreactors & 55.72586 & 60.73759 \\
\hline 26 & Electro dialysis & 47.4637 & 37.60476 \\
\hline 27 & Phenol and Ammonia Removal & 48.12719 & 38.64492 \\
\hline 28 & Air Dehydration & 48.12719 & 42.90568 \\
\hline 29 & Hydrocarbon Removal from Water & 52.10305 & 49.93593 \\
\hline 30 & Soluble Gas Removal from Water & 52.10305 & 44.32406 \\
\hline 31 & Olefin/Paraffin Separation & 48.62856 & 36.94462 \\
\hline 32 & Acid Gas Removal & 50.09365 & 37.63401 \\
\hline
\end{tabular}


Table 2. R\&D Priorities and Acquisition Modes of Membrane Technology in Iranian Petrochemical Industry

\begin{tabular}{|c|c|c|c|c|}
\hline ID & Technology & $\begin{array}{l}\text { Place in the } \\
\text { Matrix }\end{array}$ & $\begin{array}{c}\text { Suggested Acquisition } \\
\text { Mode }\end{array}$ & $\begin{array}{c}\text { R\&D Priority in } \\
\text { Petrochemical } \\
\text { Industry } \\
\end{array}$ \\
\hline 1 & Hydrogen Separation & $1^{\text {st }}$ Region & Internal R\&D & 1 \\
\hline 2 & Air Separation & $2^{\text {nd }}$ Region & Internal R\&D & 2 \\
\hline 3 & Hydrocarbon Separation & $1^{\text {st }}$ Region & Internal $R \& D$ & 1 \\
\hline 4 & Dehydration & $2^{\text {nd }}$ Region & Internal R\&D & 2 \\
\hline 5 & MTBE dehydration & $3^{\text {rd }}$ Region & Ignore & No Priority \\
\hline 6 & VCM dehydration & $3^{\text {rd }}$ Region & Ignore & No Priority \\
\hline 7 & Glycols dehydration & $3^{\text {rd }}$ Region & Ignore & No Priority \\
\hline 8 & EDC dehydration & $3^{\text {rd }}$ Region & Ignore & No Priority \\
\hline 9 & Methanol/ $\mathrm{H}_{2} \mathrm{O}$ & $3^{\text {rd }}$ Region & Ignore & No Priority \\
\hline 10 & Benzene/ $\mathrm{H}_{2} \mathrm{O}$ & $2^{\text {nd }}$ Region & Ignore & No Priority \\
\hline 11 & Butanol/ $\mathrm{H}_{2} \mathrm{O}$ & $2^{\text {nd }}$ Region & Ignore & No Priority \\
\hline 12 & Ethyl Benzene / Styrene & $3^{\text {rd }}$ Region & Ignore & No Priority \\
\hline 13 & Ethyl Benzene / xylene & $3^{\text {rd }}$ Region & Ignore & No Priority \\
\hline 14 & Xylene Isomers Separation & $3^{\text {rd }}$ Region & Ignore & No Priority \\
\hline 15 & Benzene / Gasoline & $3^{\text {rd }}$ Region & Ignore & No Priority \\
\hline 16 & Methanol / MTBE & $3^{\text {rd }}$ Region & Ignore & No Priority \\
\hline 17 & Esterification & $2^{\text {nd }}$ Region & Internal R\&D & 5 \\
\hline 18 & Dehydrogenation & $2^{\text {nd }}$ Region & Internal $R \& D$ & 5 \\
\hline 19 & Synthesis Gas Production & $2^{\text {nd }}$ Region & Internal R\&D & 5 \\
\hline 20 & Oxidative Coupling Methane (OCM) & $2^{\text {nd }}$ Region & Internal $R \& D$ & 5 \\
\hline 21 & Reverse osmosis & $2^{\text {nd }}$ Region & $\begin{array}{c}\text { Technology Process } \\
\text { Transfer- Buying the } \\
\text { product }\end{array}$ & 3 \\
\hline 22 & Nanofiltration & $2^{\text {nd }}$ Region & Internal $R \& D$ & 3 \\
\hline 23 & Ultra filtration & $2^{\text {nd }}$ Region & $\begin{array}{c}\text { Technology Process } \\
\text { Transfer- Buying the } \\
\text { product }\end{array}$ & 3 \\
\hline 24 & Microfiltration & $2^{\text {nd }}$ Region & $\begin{array}{c}\text { Technology Process } \\
\text { Transfer- Buying the } \\
\text { product }\end{array}$ & 3 \\
\hline 25 & Membrane bioreactors & $1^{\text {st }}$ Region & Internal $R \& D$ & 1 \\
\hline 26 & Electro dialysis & $2^{\text {nd }}$ Region & Internal $R \& D$ & 3 \\
\hline
\end{tabular}




\begin{tabular}{||c|l|c|c|c||}
\hline ID & \multicolumn{1}{|c|}{ Technology } & $\begin{array}{c}\text { Place in the } \\
\text { Matrix }\end{array}$ & $\begin{array}{c}\text { Suggested Acquisition } \\
\text { Mode }\end{array}$ & $\begin{array}{c}\text { R\&D Priority in } \\
\text { Petrochemical } \\
\text { Industry }\end{array}$ \\
\hline 27 & Phenol and Ammonia Removal & $\mathbf{2}^{\text {nd }}$ Region & Internal $\mathbf{R} \& \boldsymbol{D}$ & $\mathbf{4}$ \\
\hline 28 & Air Dehydration & $\mathbf{2}^{\text {nd }}$ Region & Internal $\boldsymbol{R} \& \boldsymbol{D}$ & $\mathbf{4}$ \\
\hline 29 & Hydrocarbon Removal from Water & $\mathbf{2}^{\text {nd }}$ Region & Internal $\mathbf{R} \& \boldsymbol{D}$ & $\mathbf{5}$ \\
\hline 30 & Soluble Gas Removal from Water & $\mathbf{2}^{\text {nd }}$ Region & Internal $\boldsymbol{R} \& \boldsymbol{D}$ & $\mathbf{4}$ \\
\hline 31 & Olefin/Paraffin Separation & $\mathbf{2}^{\text {nd }}$ Region & Internal $\mathbf{R} \& \boldsymbol{D}$ & $\mathbf{5}$ \\
\hline 32 & Acid Gas Removal & $\mathbf{2}^{\text {nd }}$ Region & Internal $\mathbf{R} \& \boldsymbol{D}$ & $\mathbf{5}$ \\
\hline
\end{tabular}

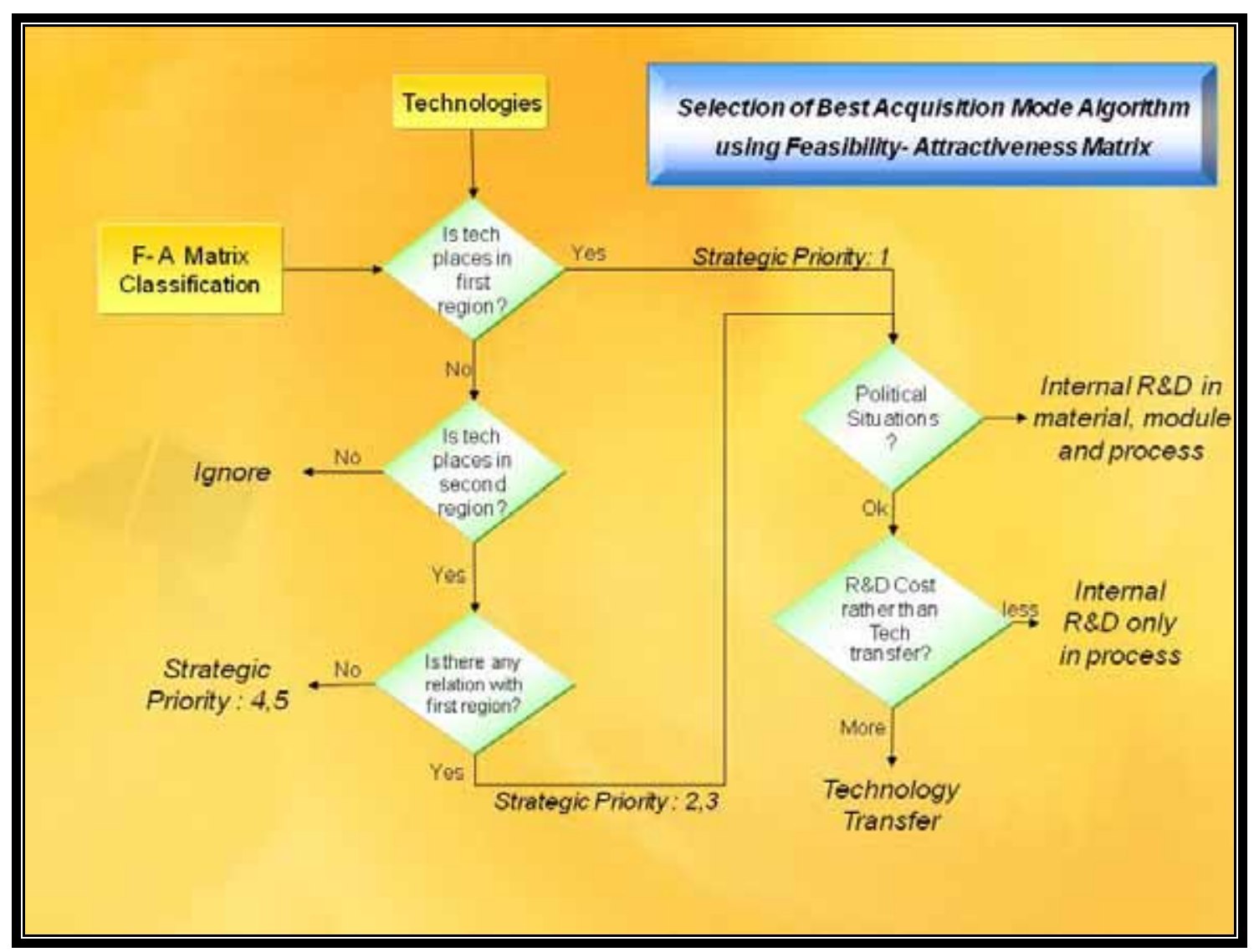

Figure 1. Proposed algorithm for selection of the best acquisition mode of prior technologies 


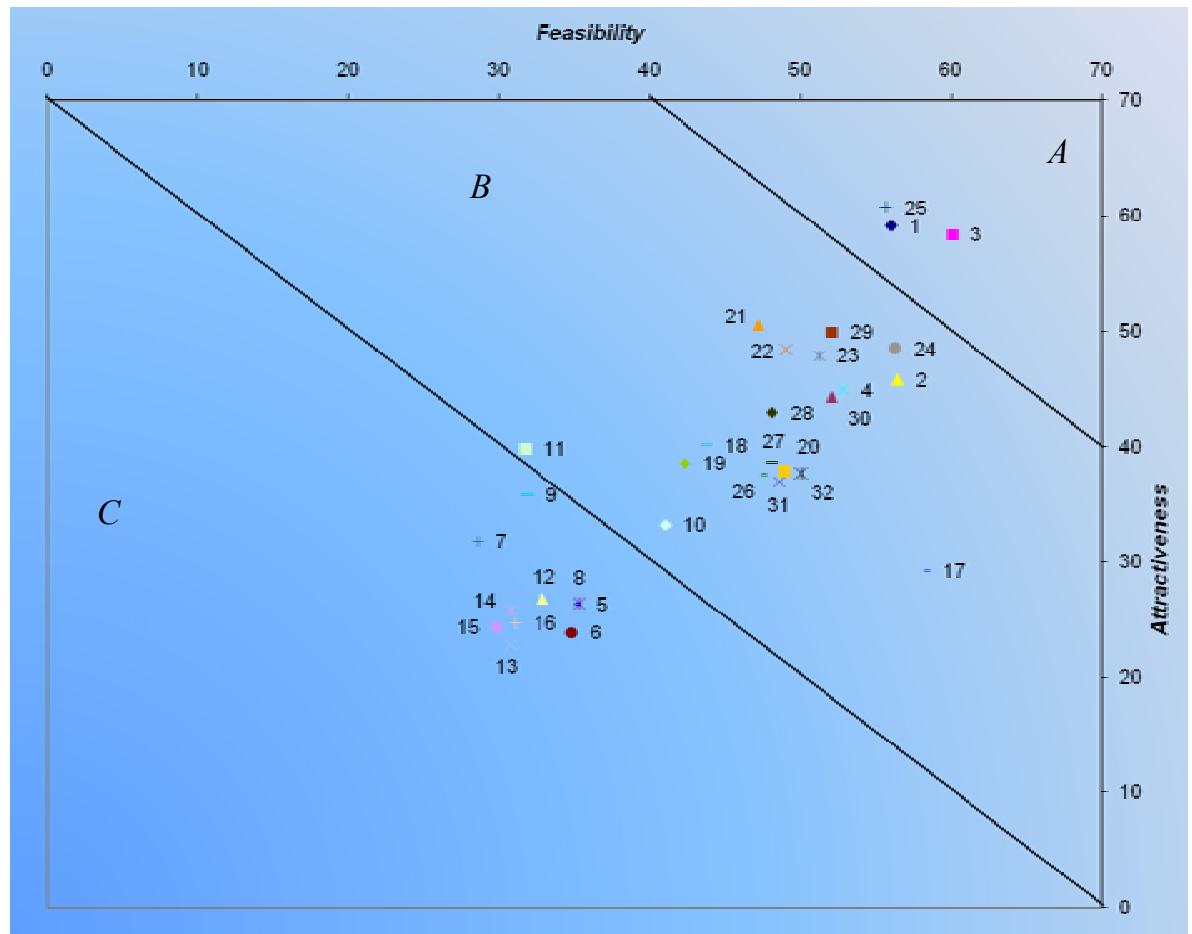

Figure 2. Feasibility-Attractiveness Matrix 